\title{
A TEORIA DA GENERALIZAÇÃO DE M. SINGER
}

Jaime José Rauber*

SÍNTESE - Com a teoria da generalização de Marcus Singer, procuro mostrar que a proposta de legitimação de normas morais universais que não considerar também as circunstâncias concretas das ações, podem legitimar normas de validade absoluta, o que pode possibilitar a justificação de ações injustas.

PALAVRAS-CHAVE - Marcus Singer, teoria da generalização, justificação, normas morais.
ABSTRACT - With the Marcus Singer's generalization theory, I try to show that the proposal of legitimatization of universal moral norms that not to also consider the concrete circumstances of the actions, they can legitimate norms of absolute validity, what can facilitate the justification of unjust actions.

KEY WORDS - Marcus Singer, theory of the generalization, justification, moral norms

Osvaldo Guariglia, em Moralidad: ética universalista y sujeto moral (1996), afirma que uma das principais questões debatidas na bibliografia ética contemporânea se refere ao principio de universalização e suas aplicações a casos especificos como critério de moralidade. Nesse sentido, o objetivo central desta comunicação é apresentar os principais elementos da teoria da generalização de Marcus Singer, que compõem a crítica e a proposta de correção do imperativo categórico kantiano, expostos na sua obra Generalization in Ethics. ${ }^{1}$ Não entrarei nas críticas a Kant propriamente ditas, mas tentarei mostrar em que consistem o Princípio da Generalização e o Argumento da Generalização os quais, na proposta de Singer, são os princípios que fundamentam a elaboração e a fixação de regras morais.

A meta de Singer, em Generalization in Ethics, é apresentar o fundamento para um sistema racional e normativo de filosofia moral. ${ }^{2}$ Contudo, não me aterei aos pormenores dessa proposta. O que pretendo é proporcionar uma idéia geral do que seja a teoria da generalização de Marcus Singer, pensamento esse que, para grande parte dos pensadores, ainda se encontra no esquecimento, mas que contempla aspectos importantes a serem considerados no desenvolvimento de uma teoria moral.

* Mestrando no Curso de Pós-Graduação em Filosofia - PUCRS.

1 A primeira edição dessa obra foi publicada em 1961; a segunda, em 1971. Em 1975 também foi publicada uma trađução para o alemão. Por falta de connecimento da língua origina: do autor, esta comunicação foi elaborada com base na tradução feita para o alemão, cujo título é Verallgemeinerung in der Ethik.

2 "Was ich zu tun hoffe, ist, das Fundament für ein rationaies und normatives System der Moralphilosophie zu legen" (Singer, 1975, p. 26).

\begin{tabular}{|l|l|l|l|l|l|}
\hline VERITAS & Porto Alegre & v. 43 & $n^{\circ} 4$ & Dezembro 1998 & p. 1021-1030 \\
\hline
\end{tabular}




\section{1-A proposta de Singer}

O pensamento moral de Singer tem como pano de fundo a concepção de que "todos nós temos conviç̧ões morais, convicções do que é certo e do que é errado. Se não as tivéssemos, também não teríamos problemas morais. Pois, problemas morais resultam de nossas convicções morais - do fato de que elas às vezes são inadequadas, muitas vezes vagas e freqüentemente contraditórias". ${ }^{3} \mathrm{O}$ que ele pretende, portanto, é solucionar esses paradoxos, tomando como modelo uma questão com a qual certamente todos nós estamos familiarizados, qual seja: "o que aconteceria se cada um fizesse isso?". 4

Essa questão, diz Singer, é uma preparação para a idéia que a segue: "Se cada um fizesse isso, as conseqüências seriam devastadoras". ${ }^{5}$ Essa constatação negativa, em muitas das nossas situações cotidianas, serve como fundamento para se deixar de realizar determinada ação ou para se agir de outra maneira de forma a evitar conseqüências indesejáveis previsiveis. Numa eleição, por exemplo, se alguém tivesse a intenção de não votar, poderiamos apresentar o seguinte questionamento: o que aconteceria, se ninguém votasse? Se ninguém votasse, além de outras conseqüências indesejáveis, no mínimo o sistema democrático ficaria abalado. A partir disso, poder-se-ia concluir que todos os que têm direito ao voto devem votar.

Nesse exemplo é empregado um tipo de argumentação que Singer chama de Argumento da Generalização (Argument der Verallgemeinerung): "Se cada um fizesse isso, as conseqüências seriam devastadoras (ou indesejáveis); por isso, ninguém deveria agir assim". ${ }^{6}$ É esse tipo de raciocínio, bastante comum em nossas discussões morais cotidianas, que está no centro das investigações de Singer. Ele entende que o procedimento da generalização é fundamental para o desenvolvimento de uma filosofia moral. O Argumento da Generalização, porém, não é o único princípio da proposta de Singer. Dentre outros, que servem para complementar o seu Sistema Moral, está o Princípio da Generalização (Prinzip der Verallgemeinerung), que é um princípio moral necessário, pois legitima a passagem do particular para o universal, do "não cada um" para "ninguém" ou de "alguns" para "todos". Vejamos, então, em que consiste esse principio.

\section{a) O Princípio da Generalização}

Para Singer, o caráter de uma ação depende das circunstâncias em que ela é realizada. Só podemos classificar uma ação como certa ou enrada, considerando o contexto, as condições e as circunstâncias em que ela é realizada. ${ }^{7}$ Segundo o

3 "Wir alle haben moralische Überzeugungen, Überzeugungen davon, was richtig und was nicht richtig ist. Hätten wir sie nicht, so hätten wir auch keine moralischen Probleme. Denn moralische Probleme entstehen aus unseren moralischen Überzeugungen - aus der Tatsache, dass sie manchmal inadäquat, oft vage und häufig widersprüchlich sind" (Op. cit., p. 28).

4 "Was würde passsieren, wenn das jeder täte?" (Op. cit., p. 23).

5 "Wenn das jeder täte, wären die Folgen verheerend" (Op. cit., p. 23).

6 "Wenn das jeder täte, wären die Folgen verheerend (oder nicht wünschenswert); daher sollte niemand das tun" (Op. cit., p. 24).

7 "Ob wir richtig oder nicht richtig handeln, hängt von der Situation oder dem Kontext der Handlung ab oder von den Bedingungen und Umständen, unter denen wir handeln" (Op. cit., p. 34). 
autor, sabe-se, por exemplo, que em determinadas circunstâncias tem-se 0 direito de romper uma promessa, de mentir ou de tirar algo de alguém, sem antes obter a permissão para tanto. O fundamento comum para a realização de tais ações é: "Isso depende das circunstâncias" (das hängt von den Umständen ab). Se uma ação pode ser certa em um determinado contexto e em outro não, ela também pode ser certa para uma pessoa e não para outra, pressuposto que elas ajam em distintas situações. Em todo caso, porém, uma ação considerada certa para $A$, em semelhantes condições também tem que ser considerada certa para $B$. Da mesma forma, a ação de $A$ também tem que ser considerada certa para $C, D, E$..., se as circunstâncias não são essencialmente diferentes. A partir disso, Singer apresenta uma primeira formulação do Princípio da Generalização (PG): "O que é certo para um, tem que ser certo também para qualquer outro que se encontre em iguais ou semelhantes circunstâncias". ${ }^{8}$

Essa formulação, porém, pode levar a interpretações ambíguas, pois a idéia de circunstâncias (Umstände) não está bem especificada. Essa expressão, segundo Singer, pode ser entendida de duas formas: por um lado, as circunstâncias de uma ação podem ser determinadas sem referência ao agente e, por outro, com referência ao agente. Se usarmos a expressão circunstâncias no primeiro sentido, então é errado dizer que o que é certo para um tem que ser certo também para qualquer outro que se encontre em semelhantes circunstâncias. Não seria obrigação de um cego ou de um homem sem pernas, por exemplo, pular na água para salvar alguém que esteja se afogando, o que, ao contrário, pode ser a obrigação de um bom nadador. Da mesma forma, sabe-se que para um cirurgião experiente pode ser correto realizar uma operação delicada em uma situação crítica; para um estudante de medicina ou para um incompetente, ao contrário, é incorreto realizar o mesmo, independentemente de quão boas sejam suas intenções. A determinação do que é certo para alguém depende de suas qualidades pessoais como também daquilo que Singer denomina condições exteriores (äusseren Bedingungen) (cf. op. cit., p. 35-6).

Isso mostra, segundo Singer, a necessidade de se acrescentar à formulação do Princípio o aspecto pessoas com semelhantes pressuposições individuais e em semelhantes circunstâncias. O PG passa, então, a assumir a seguinte forma: "O que é certo para um também tem que ser certo para qualquer outro com semelhantes pressuposições individuais e em semelhantes circunstâncias". ${ }^{9}$ Com base nesse princípio, afirma Singer, não podemos sustentar como certa uma ação para A e julgá-la errada para $B$, sem a apresentação das condições que assegurem uma fundamental diferença entre os dois. Se alguém julga uma determinada ação como certa para si, também a julga implicitamente como certa para cada pessoa, cujas qualidades e condições não se distinguem em aspectos essenciais das suas.

\footnotetext{
8 "Was für den einen richtig ist, muss unter gleichen oder ähnlichen Umständen auch für jeden anderen richtig sein" (Op. cit., p. 34).

9 "Was für einen richtig ist, muss auch für jeden anderen mit ähnlichen individuellen Voraussetzungen und unter ähnlichen Umständen richtig sein" (Op. cit., p. 35).
} 
Essa idéia, segundo Singer, não precisa estender-se muito para encontrar suas primeiras objeções. As objeções de C. D. Broad contra o pensamento de Sidgwick cabem também reconhecidamente ao seu pensamento: tranqüilamente podemos insistir na idéia de que o que é correto para um, também tem que ser correto para qualquer outro, pressuposto que se encontre em semelhantes circunstâncias. Mas o que significa isso? Como se pode decidir, em situações isoladas, se as condições e circunstâncias dos envolvidos são semelhantes ou não? Quando de fato se pode dizer que duas pessoas são semelhantes entre si? Nâo basta dizer que pessoas com semelhantes pressuposições individuais e em semelhantes circunstâncias são pessoas cujas estruturas e circunstâncias não se diferenciam entre si em determinados aspectos essenciais, pois poderiamos perguntar: $O$ que são e quais aspectos são essenciais? (cf. op. cit., p. 39). Não vou deter-me, porém, nas análises de Singer na tentativa de solucionar esses problemas, mas quero adiantar que sua proposta pretende dar conta dessas supostas objeções.

O PG implica que "se é correto para $A$ fazer $x$, então é correto para cada semelhante a $A$ em semelhantes circunstâncias fazer $x$ (ou uma ação da espécie de $x)$. De outra forma, 0 juizo de que $A$ deveria fazer $x$ implica que qualquer outro semelhante a $A$ deveria fazer $x$ (ou uma ação da espécie de $x$ ) em semelhantes circunstâncias". ${ }^{10}$ À primeira vista, parece ser incompatível com esse princípio que existam ações que sejam corretas somente para uma determinada pessoa. Essa incompatibilidade, porém, não existe. Segundo Singer, pode ser que uma determinada ação, em determinadas circunstâncias, seja correta para $A$ e para mais ninguém. Nesse caso, $A$ constitui isoladamente uma classe, pois ninguém possui semelhantes pressuposições individuais e se encontra em semelhantes circunstâncias para realizar $d$ ou uma ação semelhante a $d$. Mas, se $B$ fosse semelhante a $A$, em determinados aspectos (essenciais para tal), então seria correto para $B$ realizar $d$.

Para demonstrar que podem existir ações que são corretas para apenas uma pessoa, Singer cita o exemplo do matrimônio. Enquanto não se poderia dizer que para o Sr. Jones seria errado manter relações sexuais com a Sra. Jones, seria a rigor incorreto para qualquer outro. Tem-se aqui uma ação que é correta apenas para uma pessoa. Mas isso, segundo Singer, não contradiz o PG. O princípio não diz que ninguém deve fazer o que não cada um deve fazer e, sim, que ninguém deve fazer o que nenhum deve fazer sem apresentar fundamentos ou justificações para isso. As relações sexuais do Sr. com a Sra. Jones são justificadas pelo fato de ele ser casado com ela. Se ele não fosse casado, as condições não estariam justificadas, e qualquer outro que fosse casado com a Sra. Jones poderia justificar suas relações sexuais mantidas com ela. Em semelhantes circunstâncias, cada um tem o direito de realizar tal ação - cada um está autorizado a ter relações sexuais com sua própria mulher, mas não com a mulher de outro (cf. op. cit., p. 55).

10 “... das Prinzip, dass für jeden mit ähnlichen individuellen Voraussetzungen und unter ähnlichen Umständen richtig sein muss, was für einen richtig ist, impliziert, dass, wenn es für $A$ richtig ist, $x$ zu tun, es für jeden, der $A$ ähnlich ist, unter ähnlichen Umständen richtig ist, $x$ zu tun (oder eine Handlung von der Art wie $x$ ). Um es anders zu sagen, das Urteil, dass $A x$ tun sollte, impliziert, dass jeder, $\operatorname{der} A$ ähnlich ist, unter ähnlichen Umständen $x$ tun sollte (oder eine Handlung von der Art wie $x)^{\prime \prime}(O p$. cit., p. 60). 
Com a aplicação do PG a esse e outros casos, Singer afirma podermos concluir que o PG não é vago, inútil ou inaplicável. A tese que ele procura defender é a de que o PG está contido em cada juízo moral ou será pressuposto dele (von ihm vorausgesetzt wird). O PG é um aspecto essencial da argumentação moral, pois é pressuposto em cada tentativa de fundamentação de um juizo moral. As razões apresentadas em casos especiais fixam ao mesmo tempo a aplicação do princípio, pois delimitam o âmbito da qualificação pessoas com semelhantes pressuposições individuais e em semelhantes circunstâncias. Disso segue-se, diz Singer, que não existe juízo moral específico independente de razöes e não pode haver fundamentação moral independente do princípio da generalização (cf. op. cit., p. 57).

Apresentado $\odot$ PG, passemos à exposição do Argumento da Generalização (AG) e ao seu esclarecimento, a partir da aplicação a casos concretos. O PG apenas diz que o que é válido para um também tem que ser válido para todas as pessoas similares e que se encontrem em similares circunstâncias; mas, isolado, é insuficiente para a elaboração e fixação de normas morais. Na proposta de Singer, as normas morais resultam do AG, no qual o PG fica implícito.

\section{b) O Argumento da Generalização}

O Argumento da Generalização de Singer tem a seguinte formulação geral: ${ }^{11}$ "Se as conseqüências de que cada um faça $x$ fossem indesejáveis, então ninguém deveria fazer $x$ ". Essa fórmula geral é deduzida da seguinte anatomia:

(I) "Se as conseqüências de que $A$ faça $x$ fossem indesejáveis, então $A$ não deveria fazer $x$ ". (Principio das Conseqüências - PC). ${ }^{12}$

(II) "Se as consequências de que cada um faça $x$ fossem indesejáveis, então nem todos deveriam fazer $x$ ". (Generalização do Princípio das Conseqüências GC) ${ }^{13}$

(III) "Se não todos devem fazer $x$, então ninguém deve fazer $x$ ". Fórmula alternativa: "Se é incorreto para um fazer $x$, então é incorreto para todos fazer $x$ " (Principio da Generalização - PG). ${ }^{14}$

Segundo Singer, o PC é um princípio moral necessário. A ele corresponde manifestamente a frase "se as conseqüências de que $A$ não faça $x$ fossem indesejáveis, então $A$ deveria fazer $x$ ". Todavia, de forma alguma the corresponde a frase "se as conseqüências de que $A$ faça $x$ fossem desejáveis, então $A$ deveria fazer $x$ ", pois essa formulação poderia justificar alguma das versões do utilitarismo, o que colocaria em risco a validez do seu pensamento.

11 Singer apresenta várias formulações ao AG, mas, no meu entender, esta é a mais inclusiva e, como veremos, é a que o autor formula como resultante da Anatomia do Argumento da Generalizaçảo Anatomie des Arguments der Verallgemeinerung.

Prinzip der Folgen: "(I) Wenn die Folgen davon, dass A $x$ tut, nicht wünschenswert wären, sollte A $x$ nicht tun" (Op. cit., p. 88).

13 Verallgemeinerung des Prinzips der Folgen: “(II) Wenn die Foigen davon, dass jeder $x$ täte, nicht wünschenswert wären, dann sollte nicht jeder $x$ tun" (Op. cit., p. 90).

14 Prinzip der Verallgemeinerung: “(III) Wenn nicht jeder $x$ tun sollte, dann sollte niemand $x$ tun. Das kann natürlich auch in einer alternativen Formulierung gesagt werden: Wenn es für jeden nicht richtig ist, $x$ zu tun, dann ist es auch für irgendeinen beliebigen nicht richtig, $x$ zu tun" (Op. cit., $p$. 91). 
O segundo passo nada mais é do que a generalização do PC. O terceiro consiste no acréscimo do PG. Os três passos são fundamentais para a formulação do AG, mas, segundo Singer, sua fórmula geral resulta expressamente de (II) e (III): "Se as conseqüências de que cada um, ao fazer $x$, fossem indesejáveis, então ninguém tem o direito de fazer $x$ ". ${ }^{15}$

Para Singer, o AG é o princípio fundamental da moral. Sua aplicação a situações concretas permite distinguir se determinada ação é moralmente correta ou não. O AG não pode, porém, ser aplicado a todos os casos, pois há situações em que a sua aplicação leva a absurdos. Embora, segundo Singer, a humanidade provavelmente padeceria de frio, se cada um passasse a produzir alimentos e, certamente, morreria de fome, se cada um passasse a fabricar roupas ou a construir casas, não se pode concluir dali que ninguém deva produzir alimentos ou construir casas (cf. op. cit., p. 24). O problema fundamental relacionado ao AG está, portanto, em determinar as condições em que o Argumento é aplicável. "Dizer que 0 argumento é válido em determinadas condições, significa que em tais condições a frase se cada um fizesse isso, as conseqüências seriam indesejáveis fornece boas razões para se concluir que agir desse modo não é correto". ${ }^{16}$

Outra idéia que precisa ser esclarecida é a passagem do particular ao universal, ou seja, do "não cada um" para "ninguém" ou de "alguns" para "todos". Essa conclusão parece estar errada, pois aparentemente é o mesmo que concluir que todos fumam pelo fato de que alguns fumam. É certo que o AG implica uma inferência (Folgerung) de "não cada um tem o direito" para "ninguém tem o direito", mas, segundo Singer, ela não é necessariamente falsa. Em questões morais, essa dedução possui um qualificativo distinto dos raciocínios lógico-dedutivos, pois é mediada pelo PG. Se aceitamos o PG, então não é errado argumentar que o que é certo para uma pessoa também tem que ser certo para qualquer outra que tenha semelhantes pressuposições individuais e se encontre em semelhantes circunstâncias.

É importante ressaltarmos, porém, que a expressão "qualquer outra" não tem a conotação de todas as pessoas, no sentido absoluto, mas se refere a todas as pessoas similares e que se encontrem em similares circunstâncias àquela para qual a ação foi definida como certa. A partir do PG, podemos dizer que é semelhante ao fumante todo aquele que fuma. Logo, o que é certo (ou errado) para um fumante também é certo (ou errado) para cada fumante que se encontre em semelhantes circunstâncias, mas não para qualquer pessoa, no sentido universal, independentemente de ser fumante ou não.

Da mesma forma que a expressão "qualquer outra" não tem conotação de "todos", num sentido absoluto, a aplicação do AG também não é válida para todo e qualquer caso. Retomemos o exemplo da produção de alimentos. Se as conse-

15 "Das Argument der Verallgemeinerung (Wenn die Folgen davon, dass jeder $x$ täte, nicht wünschenswert wären, hat niemand das Recht, $x$ zu tun) folgt klar aus PV - Prinzip der Verallgemeinerung - und VF - Verallgemeinerung des Prinzips der Folgen “ (Op. cit., p. 91).

"Zu sagen, dass das Argument unter bestimmten Bedingungen gültig sei, heisst, dass unter diesen Bedingungen der Satz, wenn das jeder täte, seien die Folgen nicht wünschenswert, einen guten Grund abgibt für die Schlussfolgerung, dass es nicht richtig ist, in dieser Weise zu handeln" (Op. cit., p. 86). 
qüências de que cada produzisse alimentos fossem indesejáveis, então, pelo paradigma do AG, resultaria que ninguém deveria produzir alimentos. $O$ que se segue desse raciocínio é obviamente um absurdo, pois, se ninguém produzisse alimentos, a humanidade morreria de fome. Seria esse um bom exemplo para se refutar o AG? Singer diz que não e apresenta razões para isso.

O AG não é valido para um argumento que pode ser invertido (umkehrbar). Tal acontece nos casos em que as consequiências de cada um fazer $x$ fossem indesejáveis, enquanto que as conseqüências de ninguém fazer $x$ fossem da mesma forma indesejáveis. $O$ exemplo da produção de alimentos é passível de inversão. "Um argumento com a formulação 'se as conseqüências de cada fazer $x$ fossem indesejáveis, então ninguém deveria fazer $x$ ' só é válido, se não for o caso de que as consequiências de que ninguém faz $x$ fossem da mesma forma indesejáveis". ${ }^{17}$ Se o argumento pode ser invertido, então a aplicação do AG não é válida.

O AG só é aplicável a argumentos de conotação moral. Produzir alimentos, fabricar roupas e construir casas, diferentemente de roubar, matar ou quebrar uma promessa, são ações moralmente indiferentes. A indiferença moral, porém, se deve à invertibilidade de tais ações. Mas o que faz com que elas sejam invertiveis, mediante a aplicação do AG e, conseqüentemente, moralmente indiferentes? Segundo Singer, a razão pela qual tais ações são invertiveis está no fato de que a descrição "produção de alimentos", "fabricação de roupas" e "construção de casas" é indeterminada, do ponto de vista moral. Para que elas pudessem ser determináveis, elas teriam que ser apresentadas dentro de um determinado contexto. A expressão "produzir alimentos", por exemplo, da forma como ela está ai é muito geral para se dizer se ela é uma ação certa ou não. Poder-se-ia dizer que isso depende do contexto: em determinadas circunstâncias, é certo produzir alimentos, noutras não (cf. op. cit., p. 102-3).

Se quisermos que a "produção de alimentos" seja moralmente determinável, então precisamos, conforme 0 autor, apresentar mais detalhes sobre essa expressão e torná-la menos geral. Se a ação for apresentada dentro de um contexto e for bem detalhada, a questão de se ela é correta ou não pode ser respondida e o AG pode ser aplicado a ela, sem cair num raciocínio invertivel. Fora de um contexto específico, não podemos dizer que cada um deva produzir alimentos, nem que ninguém deva produzir alimentos (cf. op. cit. p. 105).

Singer propõe que imaginemos uma situação na qual alguém, com uma doença contagiosa, é empregado na produção de alimentos. Nesse caso, as circunstâncias nas quais os alimentos são produzidos possibilitam que outras pessoas possam ser contagiadas pelos alimentos produzidos por aquele. Se a ação "produzir alimentos" recebe a especificação de que ela é realizada em tais circunstâncias, então ela é moralmente determinável. Se cada pessoa, que tivesse tal doença, trabalhasse na produção de alimentos, as consequiências seriam devastadoras, enquanto que as conseqüências de forma alguma seriam indesejáveis, se nenhuma pessoa dessas (que tivesse tal doença) trabalhasse na produção de alimentos.

17 "Ein Argument der Form 'Da die Folgen davon, dass jeder $x$ tut, nicht wünschenswert wären, sollte niemand $x$ tun', ist nur gültig, wenn es nicht der Fall ist, dass die Folgen davon, dass niemand $x$ tut, auch nicht wünschenswert wären" (Op. cit., p. 98). 
Disso segue-se que ninguém com tal doença contagiosa tem o direito de produzir alimentos, ou seja, não é correto em tais condições produzir alimentos. ${ }^{18}$

Além dos argumentos invertiveis, Singer também afirma que é inválida toda aplicação do AG a casos em que o argumento resulta repetivel (iterierbar). ${ }^{19}$ São repetíveis os casos em que o argumento pode ser constantemente retomado. Se cada um jantasse às $18 \mathrm{~h}$, por exemplo, não haveria ninguém que desempenhasse determinadas funções que precisam ser desempenhadas naquele horário. Pelo paradigma do AG, poderíamos argumentar, então, que ninguém tem o direito de jantar às $18 \mathrm{~h}$. Contudo, se argumentarmos que ninguém tem o direito de jantar às $18 \mathrm{~h}$, também poderíamos argumentar que ninguém tem o direito de jantar às $19 \mathrm{~h}$ ou às $20 \mathrm{~h}$ e $15 \mathrm{~min}$ ou às $21 \mathrm{~h}$ e $43 \mathrm{~min}$. Dessa possibilidade de retomada do argumento resulta que ninguém deveria jantar, independentemente do horário. Da mesma forma, alguém poderia reclamar para si o direito de não pagar impostos por ser portador do nome John Smith, com a justificação de que, se todo portador do nome John Smith não pagar impostos, as conseqüencias de forma alguma seriam indesejáveis. Contudo, todas as pessoas poderiam reclamar o mesmo direito, apontando para o seu próprio nome ou para qualquer outra particularidade. Cada pessoa seria uma exceção e ninguém estaria obrigado a pagar impostos. Por conseguinte, a aplicação do AG não é válida para argumentos repetiveis, pois poderiamos justificar uma ação que seria indesejável, se cada pessoa agisse assim.

\section{c) Principios e regras morais}

O PG e o AG são os princípios que compõem a estrutura central da proposta de Singer. Embora radiquem nas relações cotidianas, estão contidos, segundo Singer, em toda tentativa de justificação e fixação de regras morais. Como princípios, são o fundamento e a ponte para todo juízo moral válido. Independentemente das circunstâncias das ações, em cada situação moral os princípios são válidos e invariáveis, ou não seriam princípios.

As regras morais, ao contrário, não são tão amplas assim, pois não valem para todas as circunstâncias e, conseqüentemente, não podem ser absolutas. Para Singer, as regras morais são regras que determinam o que em geral é certo ou errado, embora elas não sejam explicitamente formuladas com essa restrição. A regra "não mentir", por exemplo, não diz de forma alguma que é sempre errado mentir; é errado, em geral. Dizer que uma determinada espécie de ação é errada, em geral, equivale a dizer que cada ação dessas é errada, pois, para o contrário, deve haver uma razão. Se, por outro lado, dissermos que determinado tipo de ação é sempre errado, isso significa que ações dessa espécie são erradas sob todas e quaisquer circunstâncias e que não pode haver razão para o contrário.

18 A aplicação do AG a este exemplo pressupõe que nem todos estejam com a doença. Se todos já estivessem com a doença, não haveria problemas de que alguém, com a doença, trabalhasse na produção de alimentos, pois as conseqüências não seriam devastadoras, e a questão de se tais pessoas poderiam ou näo produzir alimentos nem seria colocada (cf. op. cit., p. 106-7).

19 "Jede Anwendung des Arguments der Verallgemeinerung, die iterierbar ist, ist ungültig" (Op. cit., p. 108). 
As regras morais, na proposta de Singer, encontram o seu fundamento no AG, que contém o PG. A regra que não puder ser deduzida da aplicação do AG também não pode ser justificada. $\mathrm{O} A G$ é o procedimento a ser seguido para se justificar uma norma moral válida. A modo de ilustração, consideremos a regra de que não se deve mentir, Qual o fundamento para a validez dessa regra? Segundo Singer, o que justifica essa regra não está no fato de a maioria das pessoas desaprovarem a mentira, mas no raciocínio do que aconteceria, se cada um mentisse. Se cada um mentisse, as conseqüências seriam assoladoras; dizer a verdade passaria a ser exceção e, assim, as relações dialógicas não fariam mais sentido, pois nenhum homem acreditaria no que outro dissesse. Disso se segue que, a rigor, não é certo mentir e que ninguém tem 0 direito de mentir, sem que tenha razões para tal. Isso implica evidentemente que pode haver exceções à regra. Mas, como podemos saber que as razões apresentadas são suficientemente fortes, para se ter o direito à exceção? Novamente entra em cena o AG: se as circunstâncias de uma ação são tais que nessas ou semelhantes circunstâncias de forma alguma fosse indesejável que cada um agisse assim, então a ação de forma alguma é errada (cf. op. cit., p. 154).

Nesse sentido, se ficou suficientemente mostrado que as regras morais podem ser deduzidas do AG, seria contraditório, diz Singer, afirmar que sempre, e não somente em geral, seria falso mentir, porque as razões das quais depende a regra são as mesmas razões que, em determinadas circunstâncias, bastam para se eximir dela. ${ }^{20}$ Não obstante, deve estar claro que o $\mathrm{AG}$ não fundamenta regras morais válidas sempre, isto é, em todas e quaisquer circunstâncias, mas fundamenta regras morais válidas em geral.

\section{2- Considerações finais}

Em Kant, como de certa forma também na Ética do Discurso de Habermas, ${ }^{21}$ as leis morais resultantes dos respectivos principios formais da moralidade levam à fixação de leis absolutas, ou seja, leis que devem ser rigorosamente seguidas em todas as circunstâncias. $\mathrm{O}$ procedimento indicado pelo imperativo categórico diz que só devemos agir (ou deixar de agir), se a máxima de nossa ação puder também ser considerada como lei universal. $\mathrm{O}$ ato de mentir jamais pode ser universalizado, diz Kant, pois, se assim fosse, não faria mais sentido confiar em alguém. A partir disso, o filósofo de Königsberg conclui que jamais se deve mentir. Esse ab-

20 "Wenn sich moralische Regeln aus dem Argument der Verallgemeinerung ableiten lassen, wie ich behauptet habe, wäre es widersprüchlich zu behaupten, dass es immer und nicht nur im allgemeinen faisch wäre zu lügen, denn die Gründe, auf denen die Regel beruht, sind genau die gleichen Gründe, die unter bestimmten Umständen ausreichen, sich über sie hinwegzusetzen" (Op. cit., p. 155).

21

Da mesma forma que Kant, Habermas pretende simplesmente indicar o procedimento a ser segujdo para a fundamentação de normas morais. O procedimento, como tal, não indica conteúdos do dever, o que caracteriza sua proposta como formal, isto é, meramente proceduristica. Os conteúdos do dever, em Habermas, provém do mundo da vida, e assumem forma objetiva por meio do discurso prático racionalmente motivado. Contudo, se defendermos o puro procedimentalismo, como quer Habermas, a Ética do Discurso também cairá num rigorismo inadiável. Isso pretendo mostrar, de forma mais detaihada, na minha dissertação de mestrado. 
solutismo das regras morais fica explícito tanto na Fundamentação da Metafísica dos Costumes (1785) como na Crítica da Razão Prática (1788) e no texto Sobre um suposto direito de mentir por amor à humanidade (1797), onde Kant, contra as objeções de Benjamin Constant, tenta justificar por que jamais se deve mentir.

A questão das circunstâncias, bastante enfatizada por Singer, é fundamental para a elaboração de uma boa teoria moral, pois, se dissermos que as regras morais têm que valer, não só em geral, mas universalmente (no sentido absoluto), então implicitamente podemos estar justificando absurdos. Eis aí um aspecto fundamental a ser considerado na formulação de uma teoria moral. Pode haver situações em que uma exceção à regra é mais moral do que a sua rigorosa observância. A razão, para se infringir uma regra moral, encontra seu fundamento nas próprias circunstâncias da ação, e a legitimidade para essa infração está, conforme a proposta de Singer, no AG.

Se a proposta de Singer é bastante complexa, ou se a aplicação do seu princípio possui um grau de ambigüidade maior que o admitido por ele, como afirma Guariglia, pelo menos ela consegue mostrar a necessidade de se refutar o absolutismo das regras morais. Singer não refuta o absolutismo dos princípios morais, muito pelo contrário, defende a idéia de que eles têm que ser mais universais e abstratos do que as regras, mas não menos determinados do que aquelas.

Nesse sentido, se ainda quisermos defender Kant, no mínimo temos que corrigi-lo e mostrar que não podemos fixar regras morais absolutas que não permitem nenhuma exceção. Poderiamos até argumentar que em seu pensamento existe a possibilidade de se justificarem exceções à regra moral, mas, nesse caso, já estariamos tentando corrigir Kant, pois, se nos reportarmos à obra Sobre um suposto direito de mentir por amor à humanidade, veremos que ali o absolutismo fica explicitamente confirmado.

\section{Referências bỉbliográficas}

GUARIGLIA, Osvaldo. Moralidade: ética universalista y sujeto moral. Buenos Aires: Fondo de Cultura Económica, 1996.

HABERMAS, Jürgen. Consciência moral e agir comunicativo. Rio de Janeiro: Tempo Brasileiro, 1989. KANT, Immanuel. Crítica da Razão Prática. Lisboa: Edições 70, 1997.

- Fundamentação da Metafisica dos Costumes. Lisboa: Edições 70, 1986.

- Sobre un presunto derecho a mentir por amor al prójimo. Tradução e notas de Mario Caimi. Cuademos de Etica. n. 2-3. Buenos Aires, 1987.

SINGER, Marcus George. Verallgemeinerung in der Ethik: zur Logik moralischen Argumentierens. Frankfurt: Suhrkamp, 1975. 